\title{
Immunohistochemical Detection of Apoptosis-Related Proteins in Gerbil Hippocampus Transient Cerebral Ischemia: Neuroprotective Effect of Pitavastatin
}

\author{
${ }^{1}$ Toshiki Himeda, ${ }^{1}$ Natsumi Hayakawa, ${ }^{1}$ Hiroko Tounai, ${ }^{1}$ Aki Tanaka, \\ ${ }^{2}$ Hiroyuki Kato and ${ }^{1}$ Tsutomu Araki \\ ${ }^{1}$ Department of Drug Metabolism and Therapeutics, Faculty of Pharmaceutical Sciences, Graduate School, \\ The University of Tokushima, Tokushima, Japan \\ ${ }^{2}$ Department of Neurology, Organized Center of Clinical Medicine, \\ International University of Health and Welfare, Tochigi, Japan
}

\begin{abstract}
Delayed and selective neuronal damage was caused in the CA1 sector of hippocampus following $5 \mathrm{~min}$ of transient cerebral ischemia in gerbils. We investigated the immunohistochemical alterations of apoptosis-related proteins such as bcl-2 $\alpha$, bcl-xs/l, bax, cytochrome $c$, and active caspase 3 and TUNEL staining in the hippocampus at 1 and $5 \mathrm{hr}$ and 1,2,5 and 14 days after transient cerebral ischemia in gerbils. We also examined the effect of 3-hydroxy-3-methylglutaryl-coenzyme A reductase inhibitor pitavastatin against the alterations of apoptosis-related proteins and TUNEL staining in the hippocampus after cerebral ischemia. The alterations of apoptosis-related proteins in the hippocampal CA1 sector were more pronounced than the changes of hippocampal CA3 sector and dentate gyrus after cerebral ischemia. The alterations of apoptosis-related proteins in the hippocampal CA1 sector after cerebral ischemia preceded the neuronal damage in this region. Furthermore, the study with TUNEL staining showed that a marked increase of TUNEL-positive nuclei was evident only in the hippocampal CA1 sector 5 days after cerebral ischemia. Our immunohistochemical study also showed that pitavastatin prevented the alterations of apoptosis-related proteins and the increase of TUNEL-positive nuclei in the hippocampal CA1 sector 5 days after cerebral ischemia. The present study indicates that transient cerebral ischemia in gerbils causes the mitochondrial-dependent apoptosis in the hippocampal CA1 sector. Furthermore, our present study demonstrates that pitavastatin can prevent the alterations of apoptosis-related proteins and the increase of TUNEL-positive nuclei in the hippocampal CA1 sector after cerebral ischemia. Thus our study provides novel therapeutic strategies in clinical stroke.
\end{abstract}

Key words: Apoptosis, Immunohistochemistry, TUNEL, Pitavastatin, Gerbil

\section{INTRODUCTION}

There is increasing evidence that apoptosis, a form programmed cell death, plays a critical role in the regulation of development and maintenance of many adult tissues, including those of the nervous system ${ }^{[1]}$. Morphological and biochemical features of apoptosis has been reproducibly detected in the ischemic brain, including cell membrane protrusion, chromatin condensation, formation of apoptotic bodies, and internucleosomal DNA degradation ${ }^{[2-5]}$. It is known that apoptosis is associated with the activation of a genetic program in which apoptosis effector genes promote cell death, while repressor genes enhance cell survival. Among the apoptosis repressor genes, proto-oncogene bcl-2 has attracted the most attention. In the central nervous system (CNS), bcl-2 protein is expressed in a large population of neurons during embryonic development ${ }^{[6,7]}$, but levels are greatly reduced or undetectable in the majority of postomitotic CNS neurons of adult brains ${ }^{[8]}$. Several studies demonstrate that the cytochrome c-dependent apoptotic pathway contributes to the neuronal cell death after ischemia ${ }^{[9-}$ ${ }^{11]}$. Although cytochrome $c$ release from mitochondria is also an important event in other CNS injuries, such as brain trauma and spinal cord injury ${ }^{[12-14]}$, the upstream events of cytochrome $c$ release from mitochondria after transient cerebral ischemia are not yet fully understood.

The bcl-2 family of proto-oncogenes encodes specific proteins which regulate programmed cell death in different physiological and pathological conditions $^{[15]}$. The anti-apoptotic members of the bcl-2 family, including bcl-2 and bcl-xL, are associated with the mitochondrial outer membrane and can inhibit the release of cytochrome $c^{[16,17]}$. By contrast, bcl-2associated death promoter, such as bad, which is proapoptotic member, binds to bcl-2 and bcl-xL, and inhibits their anti-apoptotic functions. Bcl-2 $\alpha$ is also a member of a recently discovered family of proteins that are regulators of apoptosis ${ }^{[18]}$. However, the molecular

Corresponding Author: Tsutomu Araki, Ph.D., Department of Drug Metabolism and Therapeutics, Faculty of Pharmaceutical Sciences, Graduate School, The University of Tokushima, 1-78, Sho-Machi, Tokushima 770-8505, Japan Tel: +81-88-633-7277 Fax: +81-88-633-9511 
mechanisms of bcl-2 $\alpha$ against apoptosis after transient cerebral ischemia are still unclear.

A recent study demonstrates the translocation of bax to the mitochondria in mice after transient cerebral ischemia ${ }^{[19]}$. Bax is also a cytosolic protein, which in response to stressing apoptotic stimuli is activated, and translocates to mitochondria, thus initiating the apoptotic pathway. However, the exact role of the bax against the selective neuronal cell loss in the hippocampus after transient cerebral ischemia remains presently unclear.

Caspases, a family of cysteine proteases, play a key role in the control of apoptosis ${ }^{[20]}$. Fourteen distinct caspases are divided into initiator or effector caspases based on their role and position in apoptotic cascades and involved in the tight regulation of the cellular commitment to programmed cell death. Activation of caspases results in the cleavage of a variety of protein substrates that are critical in maintaining cellular integrity ${ }^{[21,22]}$. Several studies in mice with genetically ablated caspases have been reported to demonstrate decreased neuronal death after ischemic injury ${ }^{[23,24]}$. A recent study also demonstrated that neurons derived from caspase-3 knockout mice are resistant to ischemic stress $^{[25]}$. Furthermore, the administration of caspase inhibitors (z-DEVD-FMK or z-VAD-FMK) prevents ischemia-induced neuronal damage and improves neurological outcome, confirming caspase function in the delayed neuronal cell loss following ischemia ${ }^{[9,26]}$. Based on these observations, caspase 3 is thought to be critical in both apoptosis and neuronal cell death after transient cerebral ischemia.

A previous study has demonstrated that 3-hydroxy3-methyl-glutaryl-coenzyme A (HMG-CoA) reductase inhibitors can reduce cerebral ischemia and infarct size by up-regulating eNOS expression in normocholesterolemic mice ${ }^{[27]}$. Pitavastatin is a new synthetic potent and selective inhibitor of HMG-CoA reductase, the rate-limiting enzyme in cholesterol biosynthesis $^{[28]}$. This agent has been reported to lower total cholesterol and total triglyceride levels in patients with hypercholesterolemia in Japan ${ }^{[29]}$. We recently reported that pitavastatin can decrease the neuronal damage of the hippocampal CA1 sector in gerbils after transient cerebral ischemia ${ }^{[30,31]}$. However, little is known about the effect of pitavastatin against apoptosis-related proteins in the hippocampus after transient cerebral ischemia.

In the present study, therefore, we investigated the changes of apoptosis-related proteins in gerbil hippocampus following transient cerebral ischemia using an immunohistochemical study. Furthermore, we examined the effect of pitavastatin against apoptosisrelated proteins in gerbil hippocampus after transient cerebral ischemia.

\section{MATERIALS AND METHODS}

Animals and Treatments: Male adult Mongolian gerbils, weighing 60-90 g, were used. The animals were housed in an air-conditioned environment with constant temperature and a standardized light/dark schedule, food and water ad libitum. They were anesthetized with $2 \%$ halothane in a mixture of $70 \%$ $\mathrm{N}_{2} \mathrm{O}$ and $30 \% \quad \mathrm{O}_{2}$. The bilateral common carotid arteries were exposed, anesthesia was discontinued, and the arteries were clamped with aneurysm clips for 5 min. After occlusion, the aneurysm clips were removed and ischemic animals were allowed to survive for 1 and $5 \mathrm{~h}$ and $1,2,5$ and 14 days after transient cerebral ischemia. Sham-operated animals were treated in the same manner, except for the clipping of the bilateral carotid arteries. Body temperature was maintained at $37-38^{\circ} \mathrm{C}$, using a heating pad with a thermostat, throughout the experiments. Pitavastatin at a dose of 3, 10 and $30 \mathrm{mg} \mathrm{kg}^{-1}$ was administered orally for 5 days before ischemic insult. Transient cerebral ischemia was induced in mice $1 \mathrm{~h}$ after the last treatment with pitavastatin. Vehicle $(0.5 \%$ carboxymethylcellulose, CMC) was also administered in sham-operated gerbils under the same conditions. Pitavastatin was generously provided by Kowa Company, Ltd., Tokyo, Japan. All experiments were performed in accordance with the Guidelines for Animal Experiments for the Tokushima University School of Medicine.

Histopathology: The gerbils were anesthetized with intraperitoneal treatment (i.p.) of pentobarbital $(50 \mathrm{mg}$ $\mathrm{kg}^{-1}$ ) at 1 and $5 \mathrm{hr}$ and $1,2,5$ and 14 days after transient cerebral ischemia. For pitavastatin treatment, the animals were anesthetized with pentobarbital (50 $\mathrm{mg} \mathrm{kg}^{-1}$ ) i.p. at 5 days after transient cerebral ischemia. They were briefly perfused with heparinized saline by transcardiac perfusion, followed by perfusion-fixation with $3.5 \%$ formaldehyde in $0.1 \mathrm{M}$ phosphate buffer (pH 7.4) for $30 \mathrm{~min}$. After leaving the fixated animals for $60 \mathrm{~min}$ at $4^{0} \mathrm{C}$, the brains were removed and immersed in the same fixative until they were embedded in paraffin. Paraffin sections, $5 \mu \mathrm{m}$ thickness, were stained with Cresyl violet and used for histopathology. Each group consisted of 7-8 gerbils.

Immunohistochemistry: The gerbils were anesthetized with pentobarbital (50 $\mathrm{mg} \mathrm{kg}^{-1}$, i.p.) at 1 and $5 \mathrm{~h}$ and 1 , 2, 5 and 14 days after transient cerebral ischemia. For pitavastatin treatment, the animals were anesthetized with pentobarbital ( $50 \mathrm{mg} \mathrm{kg}^{-1}$, i.p.) at 5 days after transient cerebral ischemia. The brains were perfusionfixed with $4 \%$ paraformaldehyde in $0.1 \mathrm{M}$ phosphate buffer ( $\mathrm{pH}$ 7.4) following a heparinized saline flush. The brains were removed $1 \mathrm{hr}$ after perfusion fixation at $4^{\circ} \mathrm{C}$ and were immersed in the same fixative until they were embedded in paraffin. Paraffin sections, $5 \mu \mathrm{m}$ in 
thickness, of the hippocampus were used for immunohistochemistry.

For immunohistochemical studies, a Vectastain elite ABC Kit (Vector Labs. Burlingame, CA, USA), mouse anti-bcl-2 $\alpha$ monoclonal antibody (NeoMarkers, Fremont, CA, USA), rabbit anti-bcl-xs/l polyclonal antibody (Santa Cruz Biotechnology Inc., CA, USA), rabbit anti-bax polyclonal antibody (Santa Cruz Biotechnology Inc., CA, USA), rabbit antihuman/mouse caspase 3 active polyclonal antibody ( $\mathrm{R}$ and D Systems, Inc., MN, USA) and mouse anticytochrome $c$ monoclonal antibody (NeoMarkers, Fremont, CA, USA) were used.

Briefly, the paraffin sections were washed twice for $5 \mathrm{~min}$ in $0.01 \mathrm{M}$ phosphate-buffered saline (PBS, $\mathrm{pH}$ 7.4) and treated with $10 \%$ methanol / $0.3 \% \mathrm{H}_{2} \mathrm{O}_{2}$ in 0.01 M PBS for $20 \mathrm{~min}$ to quench endogenous peroxidase activity. The paraffin sections were then washed for 2 min in $0.01 \mathrm{M} \mathrm{PBS}$, followed by $60 \mathrm{~min}$ of preincubation with $10 \%$ normal horse serum. The brain sections were then incubated with anti-bcl-2 $\alpha$ monoclonal antibody (1:200), anti-bcl-xs/l polyclonal antibody (1:500), anti-bax polyclonal antibody (1:250), anti-caspase 3 active polyclonal antibody (1:500) and anti-cytochrome $c$ monoclonal antibody (1:500) overnight at $4^{0} \mathrm{C}$. The sections were incubated with secondary antibody for $60 \mathrm{~min}$ at room temperature and then with avidin-biotin peroxidase $(\mathrm{ABC})$ complex for $30 \mathrm{~min}$ at room temperature. Immunohistochemical staining with anti-bcl-2 $\alpha$ monoclonal antibody, anti-bcl$\mathrm{xs} / \mathrm{l}$ polyclonal antibody, anti-bax polyclonal antibody, anti-caspase 3 active polyclonal antibody and anticytochrome $c$ monoclonal antibody was performed using enzyme substrate kit (Vector Labs., Burlingame, CA, USA), as described previously ${ }^{[31-33]}$. Negative control study was performed using non immuned IgG or by omission of the primary antibody, which showed no notable staining.

In addition, some brain sections of gerbils after transient cerebral ischemia were double-label immunostained with anti-bcl-xs/l antibody and mouse anti-GFAP (glial fibrillary acidic protein) monoclonal antibody (Chemicon International, Temecula, CA, USA) or anti-bcl-xs/1 antibody and alpha-D-galactosylspecific isolectin $\mathrm{B}_{4}$ conjugated with horseradish peroxidase derived from Griffonia simplicifolia seeds (Isolectin $\mathrm{B}_{4}$ ) (Sigma, St Louis, MO, USA). The histochemical staining with anti-bcl-xs/l antibody was performed as described above. On the next day, double-labeled immunostaining with anti-GFAP antibody for visualization of astrocyte or isolectin $\mathrm{B}_{4}$ for visualization of microglia was performed as described previously ${ }^{[30,34-36]}$.

TUNEL staining: To detect apoptotic cells after transient cerebral ischemia, TUNEL staining was carried out using an apoptosis in situ detection kit (Wako Pure Chemical Industries, Osaka, Japan), according to the method of Kusakabe et al. ${ }^{[37]}$. Briefly, deparaffined sections were washed distilled water and treated with $20 \mu \mathrm{g} \mathrm{mL}{ }^{-1}$ proteinase $\mathrm{K}$ for $10 \mathrm{~min}$ at $37^{\circ} \mathrm{C}$. After washing with $0.01 \mathrm{M} \mathrm{PBS}$, the sections were incubated with the terminal deoxynucleotidyl transferase (TdT) solution, incubated with 3\% hydrogen peroxide for $5 \mathrm{~min}$ to block endogenous peroxidase activity, and then treated with peroxidase-conjugated antibody for $10 \mathrm{~min}$ at room temperature. After washing in $0.01 \mathrm{M}$ PBS, nick end labeling was visualized by DAB substrate kit (Vector Labs., Burlingame, CA, USA) and counterstained using hematoxylin. As a negative control, the tissue sections were incubated with TdT buffer that did not contain the enzyme. For the positive control, tissue sections were treated with DNase I prior to treatment with TdT.

Statistical analysis: The immunostaining for each antibody was graded semiquantitatively as intense (grade 3), moderate (grade 2), weak (grade 1), and not detectable (grade 0), without the examiner knowing the experimental protocols, as described previously ${ }^{[31,35,36]}$. Values were expressed as means $\pm \mathrm{SD}$, and statistical significance was evaluated with one-way ANOVA followed by Fisher's PLSD multiple comparison test for parametric analysis. For the evaluation of drug, statistical significance was performed with $F$-test followed by Dunnett's multiple comparison tests for non-parametric analysis. Each groups consisted of 5-8 gerbils.

\section{RESULTS}

Histopathology: We have recently demonstrated the histological alterations in the hippocampus after transient cerebral ischemia ${ }^{[30]}$. In brief, sham-operated gerbils showed no neuronal damage throughout the hippocampus. No neuronal damage also was detected in the gerbil hippocampus up to 2 days after transient cerebral ischemia. Five and 14 days after ischemia, severe neuronal cell loss was found in the hippocampal CA1 sector. In contrast, the administration of pitavastatin dose-dependently prevented the neuronal loss in the hippocampal CA1 sector 5 days after ischemia.

Bcl-2a immunostaining: Representative photomicrographs are presented in Fig. 1 and 2. The changes of Bcl-2 $\alpha$ immunoreactivity after transient cerebral ischemia are summarized in Table 1 and 2 . Bcl-2 $\alpha$ immunoreactivity was mildly observed in the hippocampus of sham-operated animals. No change of bcl-2 $\alpha$ immunoreactivity was detected in the hippocampal CA1 neurons up to 1 day after transient cerebral ischemia. Two days after ischemia, a significant increase of bcl-2 $\alpha$ immunoreactivity was found in the hippocampal CA1 neurons and dentate gyrus after ischemia. Thereafter, 5 and 14 days after 
ischemia, a marked decrease of bcl- $2 \alpha$ immunoreactivity was evident in the hippocampal CA1 neurons where severe neuronal damage was observed. In contrast, no change of bcl- $2 \alpha$ immunoreactivity in the hippocampal CA3 sector and dentate gyrus was observed from $1 \mathrm{~h}$ up to 14 days after transient cerebral ischemia except for a transient increase of dentate gyrus. In contrast, the administration of pitavastatin dose-dependently prevented a significant decrease of bcl- $2 \alpha$ immunoreactivity in the hippocampal CA1 neurons 5 days after ischemia.

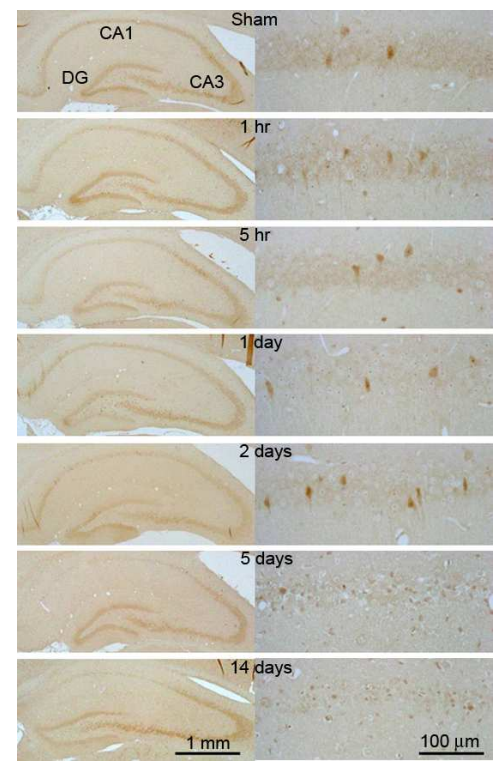

Fig. 1: Representative photomicrographs with bcl-2 $\alpha$ immunostaining of the hippocampus (left panels) and CA1 sector (right panels) after transient cerebral ischemia. Each group contained 5-8 animals. DG, dentate gyrus

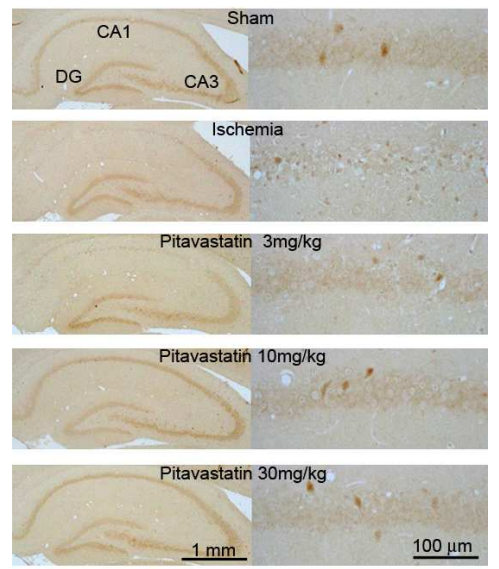

Fig. 2: Effect of pitavastatin on bcl-2 $\alpha$ immunoreactivity in the CA1 sector (right panels) of the hippocampus (left panels) of the gerbil brain 5 days after transient cerebral ischemia. Each group contained 7-8 animals
Bcl-xs/l immunostaining: Representative photomicrographs are presented in Fig. 3 and 4. The changes of bcl-xs/l immunoreactivity after transient cerebral ischemia are summarized in Table 1 and 2 . Bcl-xs/l immunoreactivity was observed mainly in glial cells of the hippocampus in sham-operated animals. A significant increase of bcl-xs/l immunoreactivity was detected in glial cells of the hippocampal CA1 sector from $5 \mathrm{~h}$ up to 14 days after transient cerebral ischemia. In contrast, no change of bcl-xs/l immunoreactivity was observed in the hippocampal CA3 sector and dentate gyrus throughout the experiments except for a transient increase of hippocampal CA3 sector. In contrast, the administration of pitavastatin dose-dependently prevented a significant increase of bcl-xs/l immunoreactivity in glial cells of the hippocampal CA1 sector 5 days after ischemia.

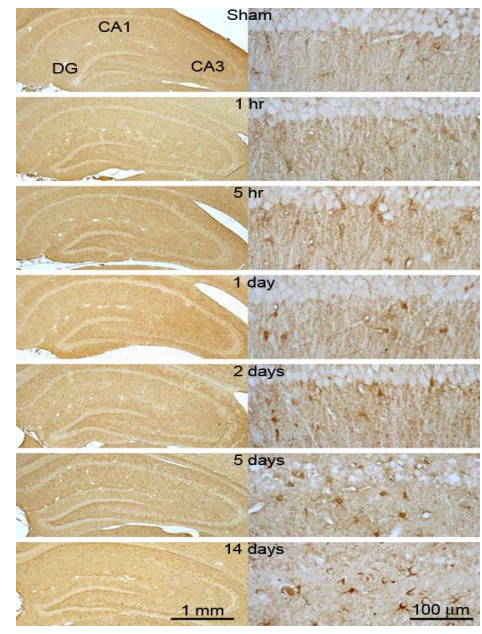

Fig. 3: Representative photomicrographs with bcl-xs/l immunostaining of the hippocampus (left panels) and CA1 sector (right panels) after transient cerebral ischemia. Each group contained 5-8 animals

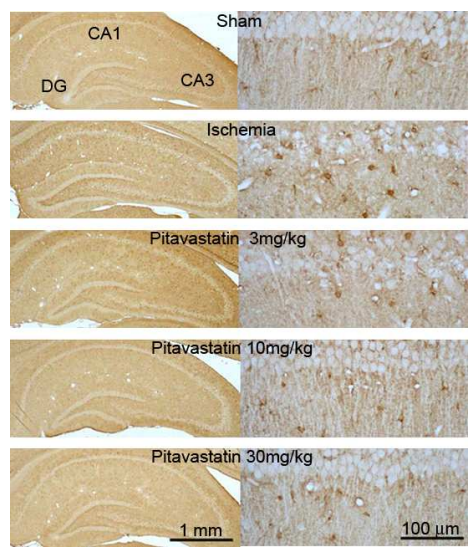

Fig. 4: Effect of pitavastatin on bcl-xs/l immunoreactivity in the CA1 sector (right panels) of the hippocampus (left panels) of the gerbil brain 5 days after transient cerebral ischemia. Each group contained 7-8 animals 
Table 1. Bcl-2 $\alpha$ and bcl-xs/l immunoreactivity in the gerbil hippocampus after transient cerebral ischemia

\begin{tabular}{llll}
\hline & CA1 & CA3 & dentate gyrus \\
\hline Bcl-2 $\alpha$ (neuron) & & & \\
Sham & $0.93 \pm 0.19$ & $0.86 \pm 0.35$ & $1.00 \pm 0.48$ \\
$1 \mathrm{hr}$ & $1.33 \pm 0.54$ & $0.79 \pm 0.25$ & $1.08 \pm 0.52$ \\
$5 \mathrm{hr}$ & $1.20 \pm 0.44$ & $0.75 \pm 0.25$ & $1.40 \pm 0.52$ \\
1 day & $1.20 \pm 0.48$ & $0.75 \pm 0.25$ & $1.30 \pm 0.51$ \\
2 days & $1.60 \pm 0.49^{* *}$ & $0.90 \pm 0.38$ & $2.20 \pm 0.21^{* *}$ \\
5 days & $0.28 \pm 0.28^{* *}$ & $0.81 \pm 0.26$ & $1.16 \pm 0.57$ \\
14 days & $0.20 \pm 0.21^{* *}$ & $0.75 \pm 0.18$ & $0.95 \pm 0.21$ \\
Bcl-xs/l (glia) & & & \\
Sham & $0.96 \pm 0.30$ & $1.11 \pm 0.48$ & $2.07 \pm 0.24$ \\
1 hr & $0.79 \pm 0.19$ & $1.00 \pm 0.22$ & $1.88 \pm 0.26$ \\
5 hr & $2.00 \pm 0.50^{* *}$ & $1.40 \pm 0.58$ & $2.10 \pm 0.38$ \\
1 day & $2.15 \pm 0.45^{* *}$ & $1.80 \pm 0.60^{* *}$ & $2.20 \pm 0.27$ \\
2 days & $1.65 \pm 0.45^{*}$ & $1.00 \pm 0.18$ & $2.10 \pm 0.29$ \\
5 days & $2.03 \pm 0.65^{* *}$ & $1.38 \pm 0.42$ & $2.28 \pm 0.34$ \\
14 days & $2.25 \pm 0.59^{* *}$ & $0.95 \pm 0.37$ & $1.95 \pm 0.33$ \\
\hline
\end{tabular}

The immunoreactivity was semiquantitatively graded as intense (grade 3 ), moderate (grade 2), weak (grade 1), and not detectable (grade 0). Values are expressed as means \pm S.D. Each group contained 5-8 animals. Statistical significance was evaluated with one-way ANOVA followed by Fisher's PLSD multiple comparison test $\left({ }^{*} P<0.05\right.$, $* * P<0.01$ compared with sham operated control group).

Table 2. Effect of pitavastatin on bcl-2 $\alpha$ and bcl-xs/l immunoreactivity in the gerbil hippocampus 5 days after transient cerebral ischemia

\begin{tabular}{llll}
\hline & CA1 & CA3 & dentate gyrus \\
\hline Bcl-2 $\alpha$ (neuron) & & & \\
Sham & $0.93 \pm 0.19^{* *}$ & $0.86 \pm 0.35$ & $1.00 \pm 0.48$ \\
Ischemia & $0.28 \pm 0.28$ & $0.81 \pm 0.26$ & $1.16 \pm 0.57$ \\
\multicolumn{2}{l}{ Ischemia + pitavastatin } & & \\
$3 \mathrm{mg} / \mathrm{kg}$ & $0.64 \pm 0.56$ & $0.61 \pm 0.20$ & $1.29 \pm 0.47$ \\
$10 \mathrm{mg} / \mathrm{kg}$ & $0.89 \pm 0.43^{*}$ & $0.71 \pm 0.17$ & $0.86 \pm 0.38$ \\
$30 \mathrm{mg} / \mathrm{kg}$ & $0.89 \pm 0.43^{*}$ & $0.50 \pm 0.00$ & $1.29 \pm 0.39$ \\
Bcl-xs/l (glia) & & & \\
Sham & $0.96 \pm 0.30^{* *}$ & $1.11 \pm 0.48$ & $2.07 \pm 0.24$ \\
Ischemia & $2.03 \pm 0.65$ & $1.38 \pm 0.42$ & $2.28 \pm 0.34$ \\
Ischemia + pitavastatin & & \\
$3 \mathrm{mg} / \mathrm{kg}$ & $1.46 \pm 0.44$ & $1.00 \pm 0.35$ & $2.04 \pm 0.17$ \\
$10 \mathrm{mg} / \mathrm{kg}$ & $1.32 \pm 0.35$ & $1.04 \pm 0.39$ & $1.96 \pm 0.17$ \\
$30 \mathrm{mg} / \mathrm{kg}$ & $1.21 \pm 0.44^{*}$ & $1.07 \pm 0.28$ & $2.00 \pm 0.00$ \\
\hline
\end{tabular}

The immunoreactivity was semiquantitatively graded as intense (grade 3 ), moderate (grade 2), weak (grade 1), and not detectable (grade 0). Values are expressed as means \pm S.D. Each group contained 7-8 animals. Statistical significance was evaluated with F-test followed by non-parametric Dunnett's multiple comparison test $\left({ }^{*} P<0.05\right.$, $* * P<0.01$ compared with ischemia group).

Bax immunostaining: Representative photomicrographs are presented in Fig. 5 and 6 . The changes of bax immunoreactivity after transient cerebral ischemia are summarized in Table 3 and 4 . Bax immunoreactivity was observed in neurons and glial cells of the hippocampus in sham-operated animals. No change of bax immunoreactivity was detected in the hippocampal CA1 neurons up to 1 day after transient cerebral ischemia. Two days after is chemia, a significant increase of bax immunoreactivity was observed in the hippocampal CA1 neurons after ischemia.
Table 3. Bax immunoreactivity in the gerbil hippocampus after transient cerebral ischemia

\begin{tabular}{llll}
\hline & CA1 & CA3 & dentate gyrus \\
\hline Bax (neuron) & & & \\
Sham & $0.75 \pm 0.14$ & $1.43 \pm 0.12$ & $1.07 \pm 0.24$ \\
$1 \mathrm{hr}$ & $0.88 \pm 0.38$ & $1.42 \pm 0.13$ & $1.13 \pm 0.14$ \\
$5 \mathrm{hr}$ & $0.60 \pm 0.14$ & $1.40 \pm 0.22$ & $1.00 \pm 0.18$ \\
1 day & $0.90 \pm 0.34$ & $1.45 \pm 0.11$ & $1.10 \pm 0.14$ \\
2 days & $1.15 \pm 0.38^{*}$ & $1.45 \pm 0.11$ & $1.20 \pm 0.11$ \\
5 days & $0.13 \pm 0.13^{* *}$ & $1.56 \pm 0.11$ & $1.06 \pm 0.11$ \\
14 days & $0.10 \pm 0.22^{* *}$ & $1.35 \pm 0.22$ & $1.05 \pm 0.11$ \\
\hline Bax (glia) & & & \\
Sham & $0.25 \pm 0.25$ & $0.32 \pm 0.40$ & $0.36 \pm 0.24$ \\
1 hr & $0.17 \pm 0.20$ & $0.33 \pm 0.30$ & $0.38 \pm 0.14$ \\
5 hr & $0.30 \pm 0.21$ & $0.55 \pm 0.21$ & $0.35 \pm 0.22$ \\
1 day & $0.30 \pm 0.21$ & $0.45 \pm 0.27$ & $0.40 \pm 0.17$ \\
2 days & $0.35 \pm 0.34$ & $0.40 \pm 0.29$ & $0.40 \pm 0.29$ \\
5 days & $1.69 \pm 0.51 * *$ & $0.44 \pm 0.40$ & $0.53 \pm 0.28$ \\
14 days & $2.60 \pm 0.38^{* *}$ & $0.40 \pm 0.17$ & $0.55 \pm 0.27$ \\
\hline
\end{tabular}

The immunoreactivity was semiquantitatively graded as intense (grade 3 ), moderate (grade 2), weak (grade 1), and not detectable (grade 0). Values are expressed as means \pm S.D. Each group contained 5-8 animals. Statistical significance was evaluated with one-way ANOVA followed by Fisher's PLSD multiple comparison test $(* P<0.05$, $* * P<0.01$ compared with sham operated control group).

Table 4. Effect of pitavastatin on bax immunoreactivity in the gerbil hippocampus 5 days after transient cerebral ischemia

\begin{tabular}{llll}
\hline & CA1 & CA3 & dentate gyrus \\
\hline Bax (neuron) & & & \\
Sham & $0.75 \pm 0.14^{* *}$ & $1.43 \pm 0.12$ & $1.07 \pm 0.24$ \\
Ischemia & $0.13 \pm 0.13$ & $1.56 \pm 0.12$ & $1.06 \pm 0.12$ \\
Ischemia + pitavastatin & & \\
$\quad 3 \mathrm{mg} / \mathrm{kg}$ & $0.64 \pm 0.28^{* *}$ & $1.36 \pm 0.20$ & $1.07 \pm 0.12$ \\
$10 \mathrm{mg} / \mathrm{kg}$ & $0.71 \pm 0.22^{* *}$ & $1.50 \pm 0.00$ & $1.07 \pm 0.12$ \\
$30 \mathrm{mg} / \mathrm{kg}$ & $0.71 \pm 0.22^{* *}$ & $1.43 \pm 0.12$ & $1.00 \pm 0.00$ \\
Bax (glia) & & & \\
Sham & $0.25 \pm 0.25^{* *}$ & $0.32 \pm 0.40$ & $0.36 \pm 0.24$ \\
Ischemia & $1.69 \pm 0.51$ & $0.44 \pm 0.40$ & $0.53 \pm 0.28$ \\
Ischemia + pitavastatin & & \\
$3 \mathrm{mg} / \mathrm{kg}$ & $0.61 \pm 0.43$ & $0.21 \pm 0.17$ & $0.43 \pm 0.12$ \\
$10 \mathrm{mg} / \mathrm{kg}$ & $0.14 \pm 0.13^{* *}$ & $0.25 \pm 0.20$ & $0.18 \pm 0.19^{*}$ \\
$30 \mathrm{mg} / \mathrm{kg}$ & $0.21 \pm 0.17^{* *}$ & $0.32 \pm 0.28$ & $0.32 \pm 0.19$ \\
\hline
\end{tabular}

The immunoreactivity was semiquantitatively graded as intense (grade 3 ), moderate (grade 2), weak (grade 1), and not detectable (grade 0). Values are expressed as means \pm S.D. Each group contained 7-8 animals. Statistical significance was evaluated with F-test followed by non-parametric Dunnett's multiple comparison test $\left({ }^{*} P<0.05\right.$, $* * P<0.01$ compared with ischemia group).

Thereafter, a marked decrease of bax immunoreactivity was evident in the hippocampal CA1 neurons 5 and 14 days after ischemia, when severe neuronal cell loss was observed. In contrast, no change of bax immunoreactivity was found in glial cells of the hippocampal CA1 sector up to 2 days after ischemia. However, a marked increase of bax immunoreactivity was evident in glial cells of the hippocampal CA1 sector 5 and 14 days after cerebral ischemia. In the hippocampal CA3 sector and dentate gyrus, no change of bax immunoreactivity was observed in neurons and glial cells throughout the experiments. Furthermore, the administration of pitavastatin attenuated the alterations of the bax immunoreactivity in the hippocampal CA1 neurons and glial cells 5 days after ischemia. 


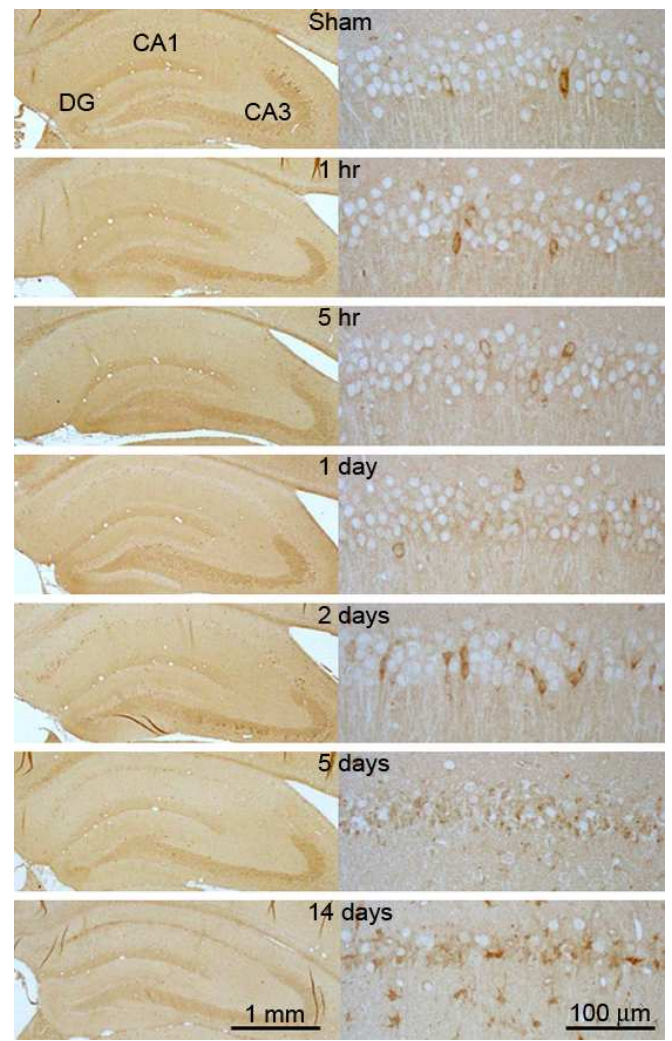

Fig. 5: Representative photomicrographs with bax immunostaining of the hippocampus (left panels) and CA1 sector (right panels) after transient cerebral ischemia. Each group contained 5-8 animals

Cytochrome c immunostaining: Representative photomicrographs are presented in Fig. 7 and 8. The changes of cytochrome c immunoreactivity after transient cerebral ischemia are summarized in Table 5 and 6. Cytochrome c immunoreactivity was observed in neurons of the hippocampus in sham-operated animals. No change of cytochrome c immunoreactivity was detected in the hippocampal CA1 neurons up to 1 day after transient cerebral ischemia. Thereafter, a marked increase of cytochrome $\mathrm{c}$ immunoreactivity was evident in the hippocampal CA1 neurons 2 days after ischemia. Five and 14 days after ischemia, a marked decrease of cytochrome c immunoreactivity was evident in the hippocampal CA1 neurons when severe neuronal cell loss was observed. In the hippocampal CA3 sector and dentate gyrus, no change of cytochrome c immunoreactivity was observed in neurons throughout the experiments except for a transient increase of the hippocampal CA3 sector and a transient decrease of the dentate gyrus. In contrast, the administration of pitavastatin dose-dependently attenuated the alteration of the cytochrome c immunoreactivity in the hippocampal CA1 neurons 5 days after ischemia.

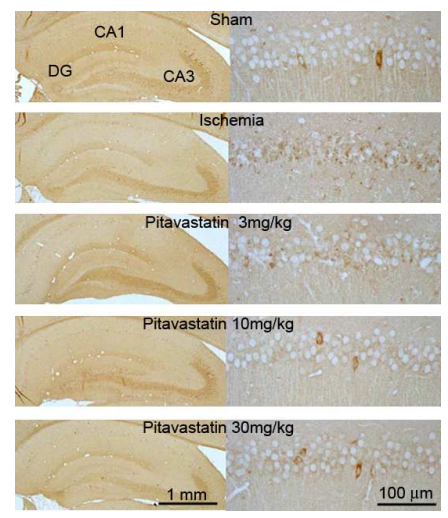

Fig. 6: Effect of pitavastatin on bax immunoreactivity in the CA1 sector (right panels) of the hippocampus (left panels) of the gerbil brain 5 days after transient cerebral ischemia. Each group contained 7-8 animals.

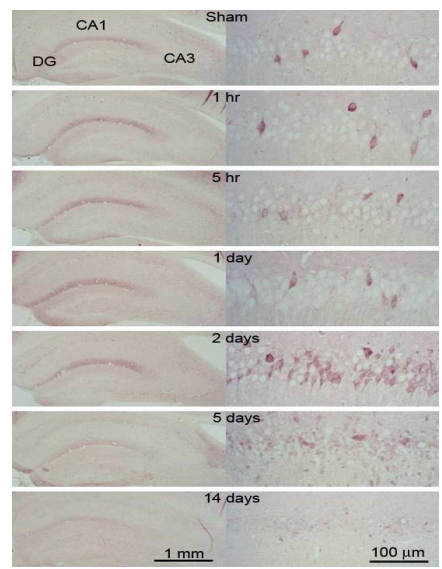

Fig. 7: Representative photomicrographs with cytochrome c immunostaining of the hippocampus (left panels) and CA1 sector (right panels) after transient cerebral ischemia. Each group contained 5-8 animals

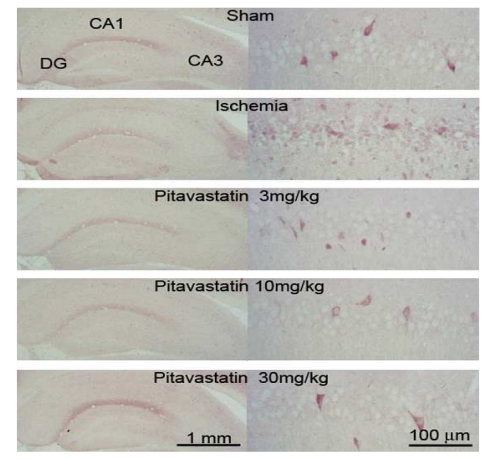

Fig. 8: Effect of pitavastatin on cytochrome $c$ immunoreactivity in the CA1 sector (right panels) of the hippocampus (left panels) of the gerbil brain 5 days after transient cerebral ischemia. Each group contained 7-8 animals. 
Table 5. Cytochrome $c$ immunoreactivity in the gerbil hippocampus after transient cerebral ischemia

\begin{tabular}{cclc}
\hline & CA1 & CA3 & dentate gyrus \\
\hline Cytochrome & $c$ (neuron) & & \\
Sham & $0.92 \pm 0.74$ & $0.11 \pm 0.20$ & $0.39 \pm 0.24$ \\
$1 \mathrm{hr}$ & $1.00 \pm 0.55$ & $0.17 \pm 0.20$ & $0.21 \pm 0.25$ \\
$5 \mathrm{hr}$ & $1.00 \pm 0.50$ & $0.56 \pm 0.32^{* *}$ & $0.20 \pm 0.11$ \\
1 day & $0.40 \pm 0.42$ & $0.10 \pm 0.14$ & $0.20 \pm 0.21$ \\
2 days & $2.20 \pm 0.57^{* *}$ & $0.40 \pm 0.14$ & $0.45 \pm 0.37$ \\
5 days & $0.19 \pm 0.26^{* *}$ & $0.28 \pm 0.39$ & $0.25 \pm 0.19$ \\
14 days & $0.10 \pm 0.22^{* *}$ & $0.10 \pm 0.14$ & $0.10 \pm 0.14^{*}$ \\
\hline
\end{tabular}

The immunoreactivity was semiquantitatively graded as intense (grade 3 ), moderate (grade 2), weak (grade 1), and not detectable (grade 0). Values are expressed as means \pm S.D. Each group contained 5-8 animals. Statistical significance was evaluated with one-way ANOVA followed by Fisher's PLSD multiple comparison test $(* P<0.05$, $* * P<0.01$ compared with sham operated control group).

Table 6. Effect of pitavastatin on cytochrome $c$ immunoreactivity in the gerbil hippocampus 5 days after transient cerebral ischemia

\begin{tabular}{|c|c|c|c|}
\hline & CA1 & CA3 & dentate gyrus \\
\hline \multicolumn{4}{|c|}{ Cytochrome $c$ (neuron) } \\
\hline Sham & $0.92 \pm 0.74 *$ & $0.11 \pm 0.20$ & $0.39 \pm 0.24$ \\
\hline Ischemia & $0.19 \pm 0.26$ & $0.28 \pm 0.39$ & $0.25 \pm 0.19$ \\
\hline \multicolumn{4}{|c|}{ Ischemia + pitavastatin } \\
\hline $3 \mathrm{mg} / \mathrm{kg}$ & $0.71 \pm 0.64$ & $0.29 \pm 0.37$ & $0.43 \pm 0.55$ \\
\hline $10 \mathrm{mg} / \mathrm{kg}$ & $0.46 \pm 0.37$ & $0.11 \pm 0.13$ & $0.14 \pm 0.20$ \\
\hline $30 \mathrm{mg} / \mathrm{kg}$ & $1.14 \pm 0.56 * *$ & $0.36 \pm 0.24$ & $0.43 \pm 0.19$ \\
\hline
\end{tabular}

The immunoreactivity was semiquantitatively graded as intense (grade 3 ), moderate (grade 2), weak (grade 1), and not detectable (grade 0). Values are expressed as means \pm S.D. Each group contained 7-8 animals. Statistical significance was evaluated with F-test followed by non-parametric Dunnett's multiple comparison test $(* P<0.05$, $* * P<0.01$ compared with ischemia group).

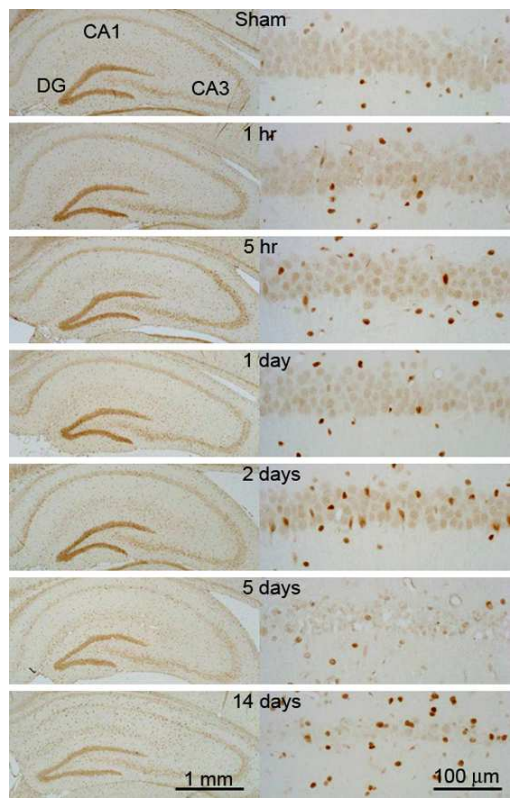

Fig. 9: Representative photomicrographs with active caspase 3 immunostaining of the hippocampus (left panels) and CA1 sector (right panels) after transient cerebral ischemia. Each group contained 5-8 animals.

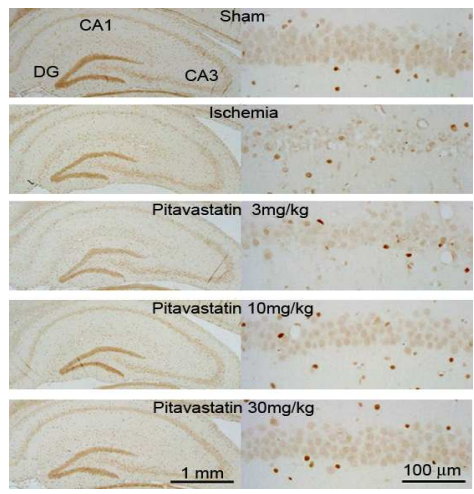

Fig. 10: Effect of pitavastatin on active caspase 3 immunoreactivity in the CA1 sector (right panels) of the hippocampus (left panels) of the gerbil brain 5 days after transient cerebral ischemia. Each group contained 7-8 animals.

Active caspase 3 immunostaining: Representative photomicrographs are presented in Fig. 9 and 10. The changes of active caspase 3 immunoreactivity after transient cerebral ischemia are summarized in Table 7 and 8 . Active caspase 3 immunoreactivity was observed in neurons and glial cells of the hippocampus in shamoperated animals. No change of active caspase 3 immunoreactivity was detected in the hippocampal CA1 neurons up to 1 day after transient cerebral ischemia. Thereafter, a significant increase of active caspase 3 immunoreactivity was evident in the hippocampal CA1 neurons 2 days after ischemia. A marked decrease of active caspase 3 immunoreactivity was observed in the hippocampal CA1 neurons 5 and 14 days after ischemia, when severe neuronal cell loss was observed. In contrast, a transient increase of active caspase 3 immunoreactivity was evident in glial cells of the hippocampal CA1 sector $5 \mathrm{hr}$ after cerebral ischemia. Thereafter, a significant decrease of active caspase 3 immunoreactivity was found in glial cells of the hippocampal CA1 sector 5 days after ischemia. However, 14 days after cerebral ischemia, a marked increase of active caspase 3 immunoreactivity was found in glial cells of the hippocampal CA1 sector. In the hippocampal CA3 sector and dentate gyrus, no change of active caspase 3 immunoreactivity was observed in neurons and glial cells throughout the experiments except for a transient increase of dentate gyrus. In contrast, the administration of pitavastatin dose-dependently attenuated the alterations of the active caspase 3 immunoreactivity in the hippocampal CA1 neurons and glial cells 5 days after ischemia.

TUNEL staining: Representative photomicrographs are presented in Fig. 11 and 12. The changes of TUNEL positive cells after transient cerebral ischemia are summarized in Table 9 and 10. TUNEL positive cells were not observed in the hippocampus of shamoperated animals. No change of TUNEL positive cells was detected in the hippocampal sector up to 2 days after transient cerebral ischemia. Five days after ischemia, a marked increase of scattered and damaged 
neurons with TUNEL positive nuclei was evident in the hippocampal CA1 sector. Thereafter, TUNEL positive nuclei were not observed in the hippocampal CA1 sector 14 days after ischemia. No change of TUNEL positive cells was observed in the hippocampal CA3 sector and dentate gyrus throughout the experiments. In contrast, the administration of pitavastatin dosedependently prevented a significant increase of TUNEL positive nuclei in the hippocampal CA1 sector 5 days after ischemia.

Double-labeled immunostainings: Representative photomicrographs are presented in Fig. 13. Bcl-xs/l immunoreactivity was observed mainly in GFAPimmunoreactive astrocytes after transient cerebral ischemia. In contrast, bcl-xs/l immunoreactivity was not found in isolectin $\mathrm{B}_{4}$-immunopositive microglia after cerebral ischemia.

Table 7. Caspase 3 immunoreactivity in the gerbil hippocampus after transient cerebral ischemia

\begin{tabular}{|c|c|c|c|}
\hline & CA1 & $\mathrm{CA} 3$ & dentate gyrus \\
\hline \multicolumn{4}{|c|}{ Caspase 3 (neuron) } \\
\hline Sham & $0.57 \pm 0.19$ & $0.93 \pm 0.19$ & $2.14 \pm 0.24$ \\
\hline $1 \mathrm{hr}$ & $0.71 \pm 0.19$ & $0.92 \pm 0.13$ & $2.71 \pm 0.29 * *$ \\
\hline $5 \mathrm{hr}$ & $0.75 \pm 0.31$ & $0.85 \pm 0.14$ & $2.55 \pm 0.37$ \\
\hline 1 day & $0.60 \pm 0.22$ & $0.85 \pm 0.14$ & $2.00 \pm 0.50$ \\
\hline 2 days & $1.00 \pm 0.40 * *$ & $1.10 \pm 0.93$ & $2.25 \pm 0.35$ \\
\hline 5 days & $0.09 \pm 0.13 * *$ & $0.78 \pm 0.25$ & $1.88 \pm 0.23$ \\
\hline 14 days & $0.10 \pm 0.14 * *$ & $0.75 \pm 0.25$ & $2.00 \pm 0.47$ \\
\hline \multicolumn{4}{|c|}{ Caspase 3 (glia) } \\
\hline Sham & $1.54 \pm 0.09$ & $1.39 \pm 0.24$ & $1.50 \pm 0.52$ \\
\hline $1 \mathrm{hr}$ & $1.75 \pm 0.22$ & $1.50 \pm 0.27$ & $1.96 \pm 0.37 *$ \\
\hline $5 \mathrm{hr}$ & $1.90 \pm 0.38 *$ & $1.55 \pm 0.33$ & $1.70 \pm 0.33$ \\
\hline 1 day & $1.60 \pm 0.14$ & $1.40 \pm 0.29$ & $1.60 \pm 0.45$ \\
\hline 2 days & $1.55 \pm 0.11$ & $1.75 \pm 0.50$ & $1.90 \pm 0.29$ \\
\hline 5 days & $1.00 \pm 0.27 * *$ & $1.31 \pm 0.22$ & $1.09 \pm 0.35$ \\
\hline 14 days & $2.40 \pm 0.38 * *$ & $1.35 \pm 0.38$ & $1.30 \pm 0.33$ \\
\hline
\end{tabular}

The immunoreactivity was semiquantitatively graded as intense (grade 3 ), moderate (grade 2), weak (grade 1), and not detectable (grade 0). Values are expressed as means \pm S.D. Each group contained 5-8 animals. Statistical significance was evaluated with one-way ANOVA followed by Fisher's PLSD multiple comparison test $(* P<0.05$, $* * P<0.01$ compared with sham operated control group).

Table 8. Effect of pitavastatin on caspase 3 immunoreactivity in the gerbil hippocampus 5 days after transient cerebral ischemia

\begin{tabular}{|c|c|c|c|}
\hline & CA1 & CA3 & dentate gyrus \\
\hline \multicolumn{4}{|c|}{ Caspase 3 (neuron) } \\
\hline Sham & $0.57 \pm 0.19 * *$ & $0.93 \pm 0.19$ & $2.14 \pm 0.24$ \\
\hline Ischemia & $0.09 \pm 0.13$ & $0.78 \pm 0.25$ & $1.88 \pm 0.23$ \\
\hline \multicolumn{4}{|c|}{ Ischemia + pitavastatin } \\
\hline $3 \mathrm{mg} / \mathrm{kg}$ & $0.39 \pm 0.35$ & $0.71 \pm 0.17$ & $2.00 \pm 0.14$ \\
\hline $10 \mathrm{mg} / \mathrm{kg}$ & $0.54 \pm 0.09 * *$ & $0.75 \pm 0.20$ & $2.14 \pm 0.24$ \\
\hline $30 \mathrm{mg} / \mathrm{kg}$ & $0.71 \pm 0.37 * *$ & $0.71 \pm 0.17$ & $2.18 \pm 0.47$ \\
\hline \multicolumn{4}{|c|}{ Caspase 3 (glia) } \\
\hline Sham & $1.54 \pm 0.09 * *$ & $1.39 \pm 0.24$ & $1.50 \pm 0.52$ \\
\hline Ischemia & $1.00 \pm 0.27$ & $1.31 \pm 0.22$ & $1.09 \pm 0.35$ \\
\hline \multicolumn{4}{|c|}{ Ischemia + pitavastatin } \\
\hline $3 \mathrm{mg} / \mathrm{kg}$ & $1.43 \pm 0.19 *$ & - & - \\
\hline $10 \mathrm{mg} / \mathrm{kg}$ & $1.57 \pm 0.12 * *$ & - & - \\
\hline $30 \mathrm{mg} / \mathrm{kg}$ & $1.54 \pm 0.09 * *$ & - & - \\
\hline
\end{tabular}

The immunoreactivity was semiquantitatively graded as intense (grade 3), moderate (grade 2), weak (grade 1), and not detectable (grade 0). Values are expressed as means \pm S.D. Each group contained 7-8 animals. Statistical significance was evaluated with F-test followed by non-parametric Dunnett's multiple comparison test $(* P<0.05$, $* * P<0.01$ compared with ischemia group). -, not tested.

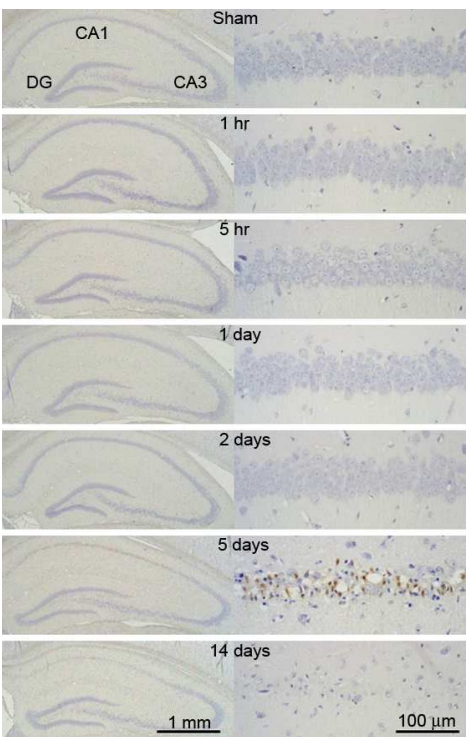

Fig. 11: Representative photomicrographs with TUNEL staining of the hippocampus (left panels) and CA1 sector (right panels) after transient cerebral ischemia. Each group contained 5-8 animals.

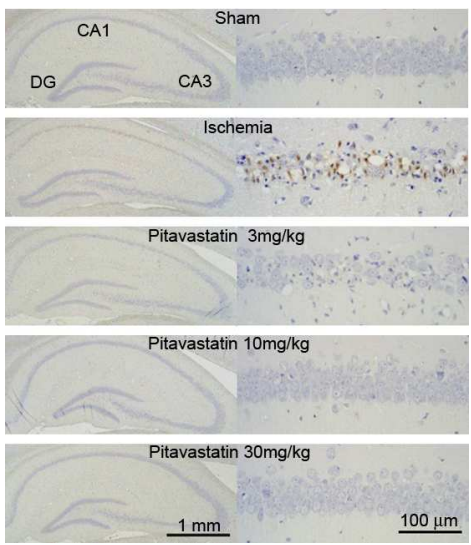

Fig. 12: Effect of pitavastatin on TUNEL staining in the CA1 sector (right panels) of the hippocampus (left panels) of the gerbil brain 5 days after transient cerebral ischemia. Each group contained 7-8 animals.
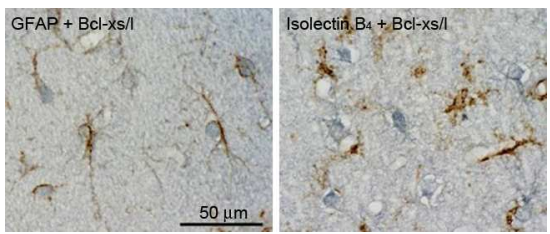

Fig. 13: Representative photomicrographs with doublelabeled immunostaining with bcl-xs/l (blue) and GFAP (brown, left panel) and with bcl-xs/1 (blue) and isolectin $\mathrm{B}_{4}$ (brown, right panel) in the CA1 sector of the gerbil brain 5 days after transient cerebral ischemia. 
Table 9. TUNEL staining in the gerbil hippocampus after transient cerebral ischemia

\begin{tabular}{cccc}
\hline & CA1 & CA3 & dentate gyrus \\
\hline TUNEL staining (neuron) & & \\
Sham & $0.0 \pm 0.0$ & $0.0 \pm 0.0$ & $0.0 \pm 0.0$ \\
$1 \mathrm{hr}$ & $0.0 \pm 0.0$ & $0.0 \pm 0.0$ & $0.0 \pm 0.0$ \\
$5 \mathrm{hr}$ & $0.0 \pm 0.0$ & $0.0 \pm 0.0$ & $0.0 \pm 0.0$ \\
1 day & $0.0 \pm 0.0$ & $0.0 \pm 0.0$ & $0.0 \pm 0.0$ \\
2 days & $0.0 \pm 0.0$ & $0.0 \pm 0.0$ & $0.0 \pm 0.0$ \\
5 days & $1.9 \pm 0.9^{* *}$ & $0.0 \pm 0.0$ & $0.0 \pm 0.0$ \\
14 days & $0.0 \pm 0.0$ & $0.0 \pm 0.0$ & $0.0 \pm 0.0$ \\
\hline
\end{tabular}

The immunoreactivity was semiquantitatively graded as intense (grade 3 ), moderate (grade 2), weak (grade 1), and not detectable (grade 0). Values are expressed as means \pm S.D. Each group contained 5-8 animals. Statistical significance was evaluated with one-way ANOVA followed by Fisher's PLSD multiple comparison test $(* P<0.05$, $* * P<0.01$ compared with sham operated control group).

Table 10. Effect of pitavastatin on TUNEL staining in the gerbil hippocampus 5 days after transient cerebral ischemia

\begin{tabular}{|c|c|c|c|}
\hline & CA1 & CA3 & dentate gyrus \\
\hline \multicolumn{4}{|c|}{ TUNEL staining (neuron) } \\
\hline Sham & $0.0 \pm 0.0 * *$ & $0.0 \pm 0.0$ & $0.0 \pm 0.0$ \\
\hline Ischemia & $1.9 \pm 0.9$ & $0.0 \pm 0.0$ & $0.0 \pm 0.0$ \\
\hline \multicolumn{4}{|c|}{ Ischemia + pitavastatin } \\
\hline $3 \mathrm{mg} / \mathrm{kg}$ & $0.6 \pm 0.8^{*}$ & $0.0 \pm 0.0$ & $0.0 \pm 0.0$ \\
\hline $10 \mathrm{mg} / \mathrm{kg}$ & $0.0 \pm 0.0 * *$ & $0.0 \pm 0.0$ & $0.0 \pm 0.0$ \\
\hline $30 \mathrm{mg} / \mathrm{kg}$ & $0.0 \pm 0.0 * *$ & $0.0 \pm 0.0$ & $0.0 \pm 0.0$ \\
\hline
\end{tabular}

The immunoreactivity was semiquantitatively graded as intense (grade 3 ), moderate (grade 2), weak (grade 1), and not detectable (grade 0). Values are expressed as means \pm S.D. Each group contained 7-8 animals. Statistical significance was evaluated with F-test followed by non-parametric Dunnett's multiple comparison test $\left({ }^{*} P<0.05\right.$, $* * P<0.01$ compared with ischemia group).

\section{DISCUSSION}

Transient cerebral ischemia in gerbils results in a delayed and selective neuronal damage in the hippocampal CA1 sector, which occurs between 3 and 7 days after bilateral common carotid occlusion ${ }^{[38,39]}$. Morphological and biochemical methods have demonstrated that this delayed neuronal death is, at least in part, due to apoptosis ${ }^{[40]}$. Caspases are believed to be the central executioner molecules of the apoptotic cell death program ${ }^{[41]}$. Caspase-dependent apoptosis may be initiated either by activation of caspases from cell surface receptors or by mitochondrial stress via cytochrome $\mathrm{c}$ release $^{[41]}$.

The Bcl-2 family of proteins regulates mitochondrial changes during both apoptosis and necrosis ${ }^{[42,43]}$. The $\mathrm{Bcl}-2$ family is divided into two groups: anti-apoptotic members include bcl-2 and bcl$\mathrm{xL}$ and pro-apoptotic members include Bax and Bid. Post-translational modification can change antiapoptotic members to pro-apoptotic form ${ }^{[44]}$. Bcl-2 and bcl-xL localize to the outer mitochondrial membrane. Bax is localized predominantly in the cytosol of health cells and translocates to mitochondria after apoptotic stimulation ${ }^{[45]}$. Several studies demonstrated changes in the levels of the bcl-2 regulators of apoptosis, translocation of cytochrome $c$ from the mitochondria to the cytosol, and caspase-3 activation after transient cerebral ischemia ${ }^{[46,47]}$. Furthermore, caspase inhibitors reduce the volume of infarct ${ }^{[9,48]}$. Based on these observations, it is conceivable that apoptosis-related proteins are key factor in neuronal cell death. However, there is no exact evidence for apoptosis-related proteins in the hippocampal CA1 sector following transient cerebral ischemia using an immunohistochemical study.

The present study showed that significant changes of bcl-2 $\alpha$ immunoreactivity were found in the hippocampal CA1 neurons 2 days after cerebral ischemia. Five and 14 days after ischemia, thereafter, bcl-2 $\alpha$ immunoreactivity decreased significantly in the hippocampal CA1 neurons where severe neuronal damage was observed. In the hippocampal CA3 sector and dentate gyrus, however, no change of bcl- $2 \alpha$ immunoreactivity was observed almost in neurons throughout the experiments. Pitavastatin dosedependently prevented a significant decrease of bcl- $2 \alpha$ immunoreactivity in the hippocampal CA1 neurons 5 days after ischemia. On the other hand, a significant increase of bcl-xs/l immunoreactivity was detected in glial cells of the hippocampal CA1 sector from $5 \mathrm{hr}$ up to 14 days after transient cerebral ischemia. No change of bcl-xs/l immunoreactivity was observed almost in the hippocampal CA3 sector and dentate gyrus throughout the experiments. Pitavastatin dosedependently prevented a significant increase of bcl-xs/l immunoreactivity in glial cells of the hippocampal CA1 sector 5 days after ischemia. These results suggest that the expression of bcl-2 $\alpha$ in neurons and bcl-xs/l in glial cells of hippocampal CA1 sector precedes the neuronal damage in the hippocampal CA1 sector. Based on these findings, we demonstrate that the expression of bcl- $2 \alpha$ in neurons and bcl-xs/l in glial cells of hippocampal CA1 sector may play a key role in the protection against cell damage after transient cerebral ischemia.

For bax immunostaining, no change of bax immunoreactivity was detected in the hippocampal CA1 neurons up to 1 day after ischemia. However, the hippocampal CA1 neurons showed a significant increase of bax immunoreactivity 2 days after ischemia. Thereafter, a marked decrease of bax immunoreactivity was evident in the hippocampal CA1 neurons 5 and 14 days after ischemia. In contrast, a marked increase of bax immunoreactivity was evident in glial cells of the hippocampal CA1 sector 5 and 14 days after cerebral ischemia. In the hippocampal CA3 sector and dentate gyrus, no change of bax immunoreactivity was observed in glial cells throughout the experiments. Pitavastatin attenuated the alterations of the bax immunoreactivity in the hippocampal CA1 neurons and glial cells 5 days after ischemia. These findings suggest that the expression of bax protein in the hippocampal CA1 neurons as well as the expression of bcl- $2 \alpha$ in neurons and bcl-xs/l in glial cells of hippocampal CA1 
sector also precedes the neuronal damage in the hippocampal CA1 sector. Therefore, the present study indicates that the expression of bax protein in the hippocampal CA1 neurons may play an important role in the acceleration against neuronal damage after ischemia.

In the present study, interestingly, the onset of the increase of bcl-2 $\alpha$ and bax immunoreactivity in the vulnerable hippocampal CA1 neurons after transient ischemia preceded apoptotic changes. These findings indicate that both proteins are involved primarily in the regulation of neuronal survival disturbed by ischemic insult. As reported recently by Nakatsuka et al. ${ }^{[49]}$, in gerbils in which ischemia-tolerance had been induced, the high level of bcl-2 immunoreactivity persists. Therefore, our results demonstrate that the activation of bcl- $2 \alpha$ protein is not sufficient to protect neuronal damage after transient ischemia, if the pro-apoptotic proteins are activated concomitantly. Furthermore, the present study suggests that the persistent expression of bcl-xs/l protein may play a key role in the protection against glial cell damage after transient cerebral ischemia, although further studies are needed to investigate the exact mechanism for our findings.

For cytochrome c immunostaining, no change of cytochrome c immunoreactivity was detected in the hippocampal CA1 neurons up to 1 day after transient cerebral ischemia. Thereafter, a marked increase of cytochrome c immunoreactivity was evident in the hippocampal CA1 neurons 2 days after ischemia. However, 5 and 14 days after ischemia, a marked decrease of cytochrome c immunoreactivity was evident in the hippocampal CA1 neurons when severe neuronal cell loss was observed. In the hippocampal CA3 sector and dentate gyrus, no change of cytochrome c immunoreactivity was observed almost in neurons throughout the experiments. Pitavastatin dosedependently attenuated the alteration of the cytochrome c immunoreactivity in the hippocampal CA1 neurons 5 days after ischemia. These present results suggest that the overexpression of cytochrome c may be involved in the hippocampal CA1 neuronal damage after transient cerebral ischemia.

For active caspase 3 immunostaining, no change of active caspase 3 immunoreactivity was detected in the hippocampal CA1 neurons up to 1 day after transient cerebral ischemia. Thereafter, a significant increase of active caspase 3 immunoreactivity was evident in the hippocampal CA1 neurons 2 days after ischemia. A marked decrease of active caspase 3 immunoreactivity was observed in the hippocampal CA1 neurons 5 and 14 days after ischemia, when severe neuronal cell loss was observed. In contrast, a significant decrease of active caspase 3 immunoreactivity was found in glial cells of the hippocampal CA1 sector 5 days after ischemia. However, 14 days after ischemia, a marked increase of active caspase 3 immunoreactivity was observed in glial cells of the hippocampal CA1 sector.
In the hippocampal CA3 sector and dentate gyrus, no change of active caspase 3 immunoreactivity was observed almost in neurons and glial cells throughout the experiments. Pitavastatin dose-dependently attenuated the alterations of the active caspase 3 immunoreactivity in the hippocampal CA1 neurons and glial cells 5 days after ischemia. The present study demonstrates that the expression of active caspase 3 protein as well as the expression of bax protein in the hippocampal CA1 neurons may play a key role in the acceleration against cell damage after ischemia.

For TUNEL staining, no change of TUNEL positive cells was detected in the hippocampal CA1 sector up to 2 days after transient cerebral ischemia. Five days after ischemia, a marked increase of TUNEL positive nuclei was evident in the hippocampal CA1 sector. Thereafter, TUNEL positive nuclei were not observed in the hippocampal CA1 sector 14 days after ischemia. No change of TUNEL positive cells was observed in the hippocampal CA3 sector and dentate gyrus throughout the experiments. Pitavastatin dose-dependently prevented a significant increase of TUNEL positive nuclei in the hippocampal CA1 sector 5 days after ischemia. These findings suggest that transient cerebral ischemia can cause apoptosis in the hippocampal CA1 neurons. Furthermore, our study shows that the administration of pitavastatin can protect hippocampal CA1 neurons from cell death with a reduced number of TUNEL positive cells.

Apoptosis contributes to be development of neuronal ischemic infarction after both global and focal ischemia $^{[5,40,50]}$. In mammalian cells, two major apoptosis signaling pathways have been described, namely the death receptor and the mitochondrial pathways. The mitochondrial pathway is activated by the release of pro-apoptotic molecules from mitochondria, such as cytochrome $c$ and Smac/DIABLO ${ }^{[51,52]}$. Once released, cytochrome $c$ forms a complex with Apaf-1 (apoptotic protease activating facto-1) and pro-caspase 9 , which results in caspase 3 activation, cleavage of cellular substrates and cell death ${ }^{[51,53,54]}$. The translocation of cytochrome $c$ and caspase 3 activation has been demonstrated after cerebral ischemia in gerbils ${ }^{[47,55]}$. Our present results suggest that the overexpressions of bax and cytochrome $c$ precede the neuronal damage in the hippocampal CA1 sector after transient cerebral ischemia in gerbils. Furthermore, the present study shows that the activation of caspase-3 precedes the neuronal damage in the hippocampal CA1 sector following transient cerebral ischemia. Based on these findings, we speculate that the activation of caspase 3 after cerebral ischemia might be contributed to the mitochondrial pathway through cytochrome $c$ release, although further work is needed to understand this aspect of apoptosis signaling.

Of particular interest in the present study is that anti-apoptotic protein bcl-xs/l was expressed mainly in GFAP-immunoreactive astrocytes, but not in isolectin 
$\mathrm{B}_{4}$-immunopositive microglia. It is known that overexpression of the anti-apoptotic protein bcl-xl can reduce astrocyte death ${ }^{[56]}$. These findings suggest that the persistent expression of anti-apoptotic protein bcl$\mathrm{xs} / \mathrm{l}$ may play a key role in the protection against astrocyte death after ischemia. In the present study, however, the expression of active caspase 3 was observed in glial cells of hippocampal CA1 sector 5 or 14 days after ischemia. The reason for this phenomenon is presently unclear. However, Petito et al. ${ }^{[57]}$ reported that scattered astrocytes with apoptotic bodies and DNA fragmentation were observed in thalamus and cortex, but without any apparent spatial correlation between neuron death and astrocyte death after $10 \mathrm{~min}$ of global ischemia in rats. Therefore, the expression of active caspase 3 in glial cells of the hippocampal CA1 sector at late stage after transient ischemia may indicate an effect of these interventions on apoptosis in astrocytes as well as in neurons, although an indirect effect on astrocyte survival can not be entirely excluded.

Pitavastatin is a new potent HMG-CoA reductase inhibitor with prolonged action and has been approved for treatment of hyperlipoproteinemia ${ }^{[58]}$. This drug is known to lower plasma total cholesterol levels and reduce triglyceride levels ${ }^{[59]}$. Furthermore, pitavastatin possesses a 10-fold higher cholesterol-lowering effect, compared with other HMG-CoA reductase inhibitors such as pravastatin and simvastatin ${ }^{[28,60]}$. A recent interesting study indicates that long-term treatment with pitavastatin in effective and safe for patients with heterozygous familial hypercholesterolemia ${ }^{[61]}$. Based on these findings, it is conceivable that pitavastatin is a new and potentially superior therapeutic agent in comparison with currently available other statins. Furthermore, a previous study demonstrates that prophylactic treatment with $\mathrm{HMG}-\mathrm{CoA}$ reductase inhibitors can decrease the severity of cerebral focal ischemic damage irrespective of serum cholesterol levels ${ }^{[27]}$. A recent study also suggests that simvastatin can inhibit several immunological properties of microglia, which may provide a rational for statin treatment in multiple sclerosis ${ }^{[62]}$. We recently reported that pitavastatin can protect against the hippocampal CA1 neuron and interneuron damage after transient cerebral ischemia in gerbils ${ }^{[30,31,36]}$. Based on these observations and our findings, it is conceivable that HMG-CoA reductase inhibitor pitavastatin are effective against transient cerebral ischemia. The present study indicates that prophylactic treatment with pitavastatin can prevent a significant increase of TUNEL positive nuclei in the hippocampal CA1 sector 5 days after transient cerebral ischemia. Our immunohistochemical study also demonstrates that pitavastatin can prevent the alterations of apoptosis-related proteins in the hippocampal CA1 sector after transient cerebral ischemia. Taken together, these data support the hypothesis that HMG-CoA reductase inhibitors can prevent the mitochondrial-dependent apoptosis after transient cerebral ischemia in gerbils, although further studies are needed to investigate the exact mechanism for our findings.

\section{CONCLUSION}

In conclusion, the present study indicates that transient cerebral ischemia in gerbils causes the mitochondrial-dependent apoptosis in the hippocampal CA1 sector. Furthermore, our present study demonstrates that pitavastatin can prevent the alterations of apoptosis-related proteins and the increase of TUNEL-positive nuclei in the hippocampal CA1 sector after cerebral ischemia. Thus our study provides novel therapeutic strategies in clinical stroke.

\section{ACKNOWLEDGMENT}

This study was supported in part by the Grant-inAid for Scientific Research (12877163, 13671095 and 13670627) from the Ministry of Science and Education in Japan and the Grant for Promoted Research from Foundation of Koujinkai.

\section{REFERENCES}

1. Saunders, J. Jr., 1966. Death in embryonic systems. Science 154: 604-612.

2. Linnik, M.D., R.H. Zobrist and M.D. Hatfield, 1993. Evidence supporting a role for programmed cell death in focal cerebral ischemia in rats. Stroke 24: 2008-2009.

3. MacManus, J.P., A.M. Buchan, I.E. Hill, I. Rasquinha and E. Preston, 1993. Global ischemia can cause DNA fragmentation indicative of apoptosis in rat brain. Neurosci. Lett. 164: 89-92.

4. Li, Y., M. Chopp, N. Jiang, F. Yao and Z. Zaloga, 1995. Temporal profile of in situ DNA fragmentation after transient middle cerebral artery occlusion in the rat. J. Cereb. Blood Flow Metab. 15: 389-397.

5. Li, Y., V.G. Sharov, N. Jiang, C. Zaloga, H.N. Sabbah and M. Chopp, 1995. Ultrastructural and light microscopic evidence of apoptosis after middle cerebral artery occlusion in the rat. Am. J. Pathol. 146: 1045-1051.

6. LeBurn, D.P., R.A. Warnke and M.L. Cleary, 1993. Expression of bcl-2 in fetal tissues suggests a role in morphogenesis. Am. J. Pathol. 142: 743753.

7. Novack, D.V. and S.J. Korsmeyer, 1994. Bcl-2 protein expression during murine development. Am. J. Pathol. 145: 61-73.

8. Merry, D.E., D.J. Veis, W.F. Hickey and S.J. Korsmeyer, 1994. bcl-2 protein expression is widespread in the developing nervous system and retained in the adult PNS. Development 120: 301311. 
9. Endres, M., S. Namura, M. Shimizu-Sasamata, C. Waeber, L. Zhang, T. Gomez-Isla, B.T. Hyman and M.A. Moskowicz, 1998. Attenuation of delayed neuronal death after mild focal ischemia in mice by inhibition of the caspase family. J. Cereb. Blood Flow Metab. 18: 238-247.

10. Fink, K., J. Zhu, S. Namura, M. Shimizu-Sasamata, M. Endres, J. Ma, T. Dalkara, J. Yuan and M.A. Moskowitz, 1998. Prolonged therapeutic window for ischemic brain damage caused by delayed caspase activation. J. Cereb, Blood Flow Metab. 18: 1071-1076.

11. Namura, S., J. Zhu, K. Fink, M. Endres, A. Srinivasan, K.J. Tomaselli, J. Yuan and M.A. Moskowitz, 1998. Activation and cleavage of caspase-3 in apoptosis induced by experimental cerebral ischemia. J. Neurosci. 18: 3659-3668.

12. Zhang, X.F., X.T. Hu and F.J. White, 1998. Whole-cell plasticity in cocaine withdrawal: reduced sodium currents in nucleus accumbens neurons. J. Neurosci. 18: 488-498.

13. Springer, J.E., R.D. Azbill and R.E. Knapp, 1999. Activation of the caspase-3 apoptotic cascade in traumatic spinal cord injury. Nature Med. 5: 943946.

14. Zhang, J.M., X.L. Song and R.H. LaMotte, 1999. Enhanced excitability of sensory neurons in rats with cutaneous hyperalgesia produced by chronic comparison of the dorsal root ganglion. J. Neurophysiol. 82: 3359-3366.

15. Merry, D.E. and S.J. Korsmeyer, 1997. Bcl-2 gene family in the nervous system. Annu. Rev. Neurosci. 20: 245-267.

16. Yang, E., J. Zha, J. Jockel, L.H. Boise, C.B. Thompson and S.J. Korsmeyer, 1995. Bad, a heterodimeric partner for $\mathrm{Bcl}-\mathrm{XL}$ and $\mathrm{Bcl}-2$, displaces Bax and promotes cell death. Cell 80: 285-291.

17. Kluck, R.M., E. Bossy-Wetzel, D.R. Green and D.D. Newmeyer, 1997. The release of cytochrome c from mitochondria: a primary site for Bcl-2 regulation of apoptosis. Science 275: 1132-1136.

18. Wattenberg, B. and T. Lithgow, 2001. Targeting of C-terminal (tail)-anchored proteins: understanding how cytoplasmic activities are anchored to intracellular membrane. Traffic 2: 66-71.

19. Saito, A., T. Hayashi, S. Okuno, M. Ferrand-Drake and P.H. Chan, 2003. Overexpression of copper/zinc superoxide dismutase in transgenic mice protects against neuronal cell death after transient cerebral ischemia by blocking activation of the bad cell death signaling pathway. $J$. Neurosci. 23: 1710-1718.

20. Eldadah, B.A. and A.I. Faden, 2000. Caspase pathways, neuronal apoptosis, and CNS injury. J. Neurotrauma 17: 811-829.
21. Nicholson, D.W. and N.A. Thornberry, 1997. Caspases: killer protease. Trends Biochem. Sci. 22: 299-306.

22. Chan, S.L. and M.P. Mattson, 1999. Caspase and calpain substrates: roles in synaptic plasticity and cell death. J. Neurol. Res. 58: 167-190.

23. Hara, H., K. Fink, M. Endres, R.M. Friedlander, V. Gagliardini, J. Yuan and M.A. Moskowitz, 1997. Attenuation of transient focal cerebral ischemic injury in transgenic mice expressing a mutant ICE inhibitory protein. J. Cereb. Blood Flow Metab. 17: 370-375.

24. Schielke, G.P., G.Y. Yang, B.D. Shivers and A.L. Betz, 1998. Reduced ischemic injury in interleukin-1 $\beta$ converting enzyme-deficient mice. J. Cereb. Blood Flow Metab. 18: 180-185.

25. Le, D.A., Y. Wu, Z. Huang, K. Matsushita, N. Plesnila, J.C. Augustinack, B.T. Hyman, J. Yuan, K. Kuida, R.A. Flavell and M.A. Moskowitz, 2002. Caspase activation and neuroprotection in caspase3-deficient mice after in vivo cerebral ischemia and in vitro oxygen glucose deprivation. Proc. Natl. Acad. Sci. U.S.A. 99: 15188-15193.

26. Chen, J., T. Nagayama, K. Jin, R.A. Stetler, R.L. Zhu, S.H. Graham and R.P. Simon, 1998. Induction of caspase-3-like protease may mediate delayed neuronal death in the hippocampus after transient cerebral ischemia. J. Neurosci. 18: 49144928.

27. Endres, M., U. Laufs, Z. Huang, T. Nakamura, P. Huang, M.A. Moskowitz and J.K. Liao, 1998. Stroke protection by 3-hydroxy-3-methylglutaryl (HMG)-CoA reductase inhibitors mediated by endothelial nitric oxide synthase. Proc. Natl. Acad. Sci. U.S.A. 95: 8880-8885.

28. Aoki, T., H. Nishimura, S. Nakagawa, J. Kojima, H. Suzuki, T. Tamaki, Y. Wada, N. Yokoo, F. Sato, H. Kimata, M. Kitahara, K. Toyoda, M. Sakashita and Y. Saito, 1997. Pharmacological profile of a novel synthetic inhibitor of 3-hydroxy3-methylgluaryl-coenzyme A reductase. Arzneimittelforschung 47: 904-909.

29. Kojima, J., H. Fujino, H. Abe, M. Yoshimura, H. Kanda and H. Kimata, 1999. Identification of metabolites of NK-104, an HMG-CoA reductase inhibitor, in rat, rabbit and dog bile. Biol. Pharm. Bull. 22: 142-150.

30. Kumagai, R., C. Oki, Y. Muramatsu, R. Kurosaki, H. Kato and T. Araki, 2004. Pitavastatin, a 3hydroxy-3-methylglutaryl-conenzyme A (HMGCo-A) reductase inhibitor, reduce hippocampal damage after transient cerebral ischemia in gerbils. J. Neural. Transm. 111: 1103-1120.

31. Himeda, T., N. Hayakawa, H. Tounai, M. Sakuma, H. Kato and T. Araki, 2005. Alterations of interneurons of the gerbil hippocampus after transient cerebral ischemia: effect of pitavastatin. Neuropsychopharmacology 30: 2014-2025. 
32. Araki, T., H. Kato, X.H. Liu, K. Kogure, K. Kato and Y. Itoyama, 1994. An immunohistochemical study of parvalbumin containing interneurons in gerbil hippocampus after cerebral ischemia. Metab. Brain Dis. 9: 225-234.

33. Kurosaki, R., Y. Muramatsu, M. Michimata, M. Matsubara, H. Kato, Y. Imai, Y. Itoyama and T. Araki, 2002. Role of nitric oxide synthase against MPTP neurotoxicity in mice. Neurol. Res. 24: 655662.

34. Streit, W.J. 1990. An improved staining method for rat microglial cells using the lectin from Griffonia simplicifolia (GSA I-B4). J. Histochem. Cytochem. 38: 1683-1686.

35. Kato, H., K. Kogure, T. Araki and Y. Itoyama, 1995. Graded expression of immunomolecules on activated microglia in the hippocampus following ischemia in a rat model of ischemic tolerance. Brain Res. 694: 85-93.

36. Muramatsu, Y., R. Kurosaki, H. Kato and T. Araki, 2004. Effect of pitavastatin against expression of $\mathrm{S} 100 \square$ protein in the gerbil hippocampus after transient cerebral ischaemia. Acta Physiol. Scand. 182: 95-107.

37. Kusakabe, K., Z.L. Li, Y. Kiso and Y. Otsuki, 2005. Perforin improves the morphogenesis of mouse placenta disturbed by IL-2 treatment. Immunobiology 209: 719-728.

38. Kirino, T. 1982. Delayed neuronal death in the gerbil hippocampus following ischemia. Brain Res. 239: 57-69.

39. Araki, T., H. Kato and K. Kogure, 1989. Selective neuronal vulnerability following transient cerebral ischemia in the gerbil: Distribution and time course. Acta Neurol. Scand. 80: 548-553.

40. Nitatori, T., N. Sato, S. Waguri, Y. Karasawa, H. Araki, K. Shibanai, E. Kominami and Y. Uchiyama, 1995. Delayed neuronal death in the CA1 pyramidal cell layer of the gerbil hippocampus following transient cerebral ischemia is apoptosis. J. Neurosci. 15: 1001-1011.

41. Budihardjo, I., H. Oliver, M. Lutter, X. Luo and X. Wang, 1999. Biochemical pathways of caspase activation during apoptosis. Annu. Rev. Cell Dev. Biol. 15: 269-290.

42. Adams, J.M. and S. Cory, 1998. The Bcl-2 protein family: arbiters of cell survival. Science 281: 13221326.

43. Tsujimoto, Y. and S. Shimizu, 2000. Bcl-2 family: life-or-death switch. FEBS Lett. 466: 6-10.

44. Basanez, G., J. Zhang, B.N. Chau, G.L., Maksaev, V.A. Frolov, T.A. Brandt, J. Burch, J.M. Hardwick and J. Zimmerberg, 2001. Pro-apoptotic cleavage products of Bcl-xL from cytochrome c-conducting pores in pure lipid membranes. J. Biol. Chem. 276: 31083-31091.

45. Wolter, K.G., Y.T. Hsu, C.L. Smith, A. Nechushtan, X.G. Xi and R.J. Youle, 1997.
Movement of Bax from the cytosol to mitochondria during apoptosis. J. Cell Chem. 139: 1281-1292.

46. Chen, J., R.L. Zhu, M. Nakayama, K. Kawaguchi, K. Jin, R.A. Stetler, R.P. Simon and S.H. Graham, 1996. Expression of the apoptosis-effector gene, Bax, is up-regulated in vulnerable hippocampal CA1 neurons following global ischemia. J. Neurochem. 67: 64-71.

47. Niwa, M., A. Hara, T. Iwai, S. Wang, K. Hotta, H. Mori and T. Uematsu, 2001. Caspase activation as an apoptotic evidence in the gerbil hippocampal CA1 pyramidal cells following transient forebrain ischemia. Neurosci. Lett. 300: 103-106.

48. Himi, T., Y. Ishizaki and S. Murota, 1998. A caspase inhibitor blocks ischemia-induced delayed neuronal death in the gerbil. Eur. J. Neurosci. 10: 777-781.

49. Nakatsuka, H., S. Ohta, J. Tanaka, K. Toku, Y. Kumon, N. Maeda, M. Sakanaka and S. Sasaki, 2000. Cytochrome c release from mitochondria to the cytosol was suppressed in the ischemiatolerance-induced hippocampal CA1 region after 5min forebrain ischemia in gerbils. Neurosci. Lett. 278: 53-56.

50. Yao, H., R. Takasawa, K. Fukuda, D. Shiokawa, F. Sadanaga-Akiyoshi, S. Ibayashi, S. Tamura and H. Uchiyama, 2001. DNA fragmentation in ischemic core and penumbra in focal cerebral ischemia in rats. Mol. Brain Res. 91: 112-118.

51. Liu, X., C.N. Kim, J. Yang, R. Jemmerson and X. Wang, 1996. Induction of apoptotic program in cell-free extracts: requirement for dATP and cytochrome c. Cell 86: 147-157.

52. Verhagen, A.M., P.G. Ekert, M. Pakusch, J. Silke, L.M. Connolly, G.E. Reid, R.L. Moritz, R.J. Simpson and D.L. Vaux, 2000. Identification of DIABLO, a mammalian protein that promotes apoptosis by binding to and antagonizing IAP proteins. Cell 102: 43-53.

53. Li, P., D. Nijhawan, I. Budihardjo, S.M. Srinivasula, M. Ahmad, E.S. Alnemri and X. Wang, 1997. Cytochrome c and ATP-dependent formation of Apaf-1/caspase-9 complex initiates an apoptotic protease cascade. Cell 91: 479-489.

54. Zou, H., W.J. Henzel, X. Liu, A. Lutschg and X. Wang, 1997. Apaf-1, a human protein homologous to $\mathrm{C}$. elegans $\mathrm{CED}-4$, participates in cytochrome c-dependent activation of caspase-3. Cell 90: 405-413.

55. Antonawich, F.J. 1999. Translocation of cytochrome c following transient global ischemia in the gerbil. Neurosci. Lett. 274: 123-126.

56. Xu, L., I.L. Koumenis, J.L. Tilly and R.G. Giffard, 1999. Overexpression of bcl-xL protects astrocytes from glucose deprivation and is associated with higher glutathione, ferritin, and iron levels. Anesthesiology 91: 1036-1046. 
57. Petito, C.K., J.P. Olarte, B. Roberts, T.S. Nowak Jr. and W.A. Pulsinelli, 1998. Selective glial vulnerability following transient global ischemia in rat brain. J Neuropathol Exp. Neurol. 57: 231-238.

58. Fujimoto, H., J. Kojima, Y. Yamada, H. Kanda and H. Kimata, 1999. Studies on the metabolic fate of pitavastatin, a new inhibitor of HMG-CoA reductase (4): interspecies variation in laboratory animals and humans. Xenobio. Metabol. Dispos. 14: 79-91.

59. Kajinami, K., J. Koizumi, K. Ueda, S. Miyamoto, T. Takegoshi and H. Mabuchi, 2000. Effects of NK104, a new hydroxymethylglutaryl-coenzyme reductase inhibitor, on low-density lipoprotein cholesterol in heterozygous familial hypercholesterolemia. Am. J. Cardiol. 85: 178-183.

60. Suzuki, H., T. Aoki, T. Tamaki, F. Sato, M. Kitahara and Y. Sato, 1999. Hypolipidemic effect of NK-104, a potent HMG-CoA reductase inhibitor, in guinea pigs. Atherosclerosis 146: 259270 .
61. Noji, Y., T. Higashikata, A. Inazu, A. Nohara, K. Ueda, S. Miyamoto, K. Kajinami, T. Takegoshi, J. Koizumi and H. Mabuchi, 2002. Long-term treatment with pitavastatin (NK-104), a new HMGCoA reductase inhibitor, of patients with heterozygous familial hypercholesterolemia. Atherosclerosis 163: 157-164.

62. Kuipers, H.F., A.A. Rappert, A.M. Mommaas, E.S. Van Haastert, P. van der Valk, H.W. Boddeke, K.P. Biber and P.J. van den Elsen, 2006. Simvastatin affects cell motility and actin cytoskeleton distribution of microglia. Glia 53: 115-123. 